\title{
Perkembangan Kubah Batu, Masjid Damaskus, Perluasan Masjid Al-Haram dan Masjid Nabawi pada Masa Khalifah Abdul Malik Bin Marwan dan Walid Bin Abdul Malik
}

\author{
Itsnawati Nurrohmah Saputri \\ UIN Sunan Kalijaga \\ itsnarohmah@gmail.com
}

\begin{abstract}
This research describes the building that was built and renovated during the regimes of Khalifah Abdul Malik bin Marwan and Walid bin Abdul Malik. The method used in this study is the historical method, which uses the approach of cultural anthropology, and the theory of cultural acculturation. The technique of data collection is by literature study. The result of this research is in the era of Abdul Malik bin Marwan, built Qubat as-Shkhrah/Dome of the Rock in Jerusalem, until today become one of the greatest Islamic monuments. In the Dome of the Rock Mosque, the masonry building style mixed from Byzantine and Persian culture. In the era of Walid bin Abdul Malik built the famous grand mosque of Damascus Mosque. The construction of the mosque was also affected by the Byzantine culture, because the earlier Damascus mosque was a converted church to become a mosque. The effect on the original building form has a simple pattern, having gained influence from the outside culture adds to the shape of the building and does not change the initial shape of the initial pattern. During the reign of Khalifah Abdul Malik and al-Walid I did an expansion in Masjid al-Haram and Masjid Nabawi.
\end{abstract}

Keywords: arsitektur, Masjid, Dinasti Umayyah

\begin{abstract}
Abstrak
Penelitian ini mendeskripsikan tentang bangunan yang dibangun dan direnovasi pada masa pemerintahan Khalifah Abdul Malik bin Marwan dan Walid bin Abdul Malik. Metode yang digunakan dalam penelitian ini adalah metode historis, yang menggunakan pendekatan antropologi budaya, dan menggunakan teori akulturasi budaya. Hasil dari penelitian ini adalah pada masa Abdul Malik bin Marwan membangun Qubat as-Shkhrah/Dome of The Rock/Kubah Batu di Yerusalem, hingga saat ini menjadi salah satu monumen Islam terbesar. Pada masjid Kubah Batu gaya bangunan tercampur dari kebudayaan Bizantium dan Persia. Pada masa Walid bin Abdul Malik dibangun masjid agung yang terkenal yaitu Masjid Damaskus. Pembangunan masjid ini juga terpengaruh oleh kebudayaan Bizantium, karena Masjid Damaskus terdahulu merupakan gereja
\end{abstract}


Millatī, Journal of Islamic Studies and Humanities, Vol. 2, No. 2, Des. 2017: 195-220

yang dialih fungsikan menjadi masjid. Pengaruh terhadap bentuk bangunan yang semula memiliki pola sederhana, setelah mendapatkan pengaruh dari kebudayaan luar menambah bentuk dari bangunan dan tidak mengubah bentuk awal dari pola awal. Pada masa pemerintahan Khalifah Abdul Malik dan al-Walid I melakukan perluasaan pada Masjid al-Haram dan Masjid Nabawi.

Kata kunci: arsitektur, Masjid, Dinasti Umayyah

\section{Pendahuluan}

Perluasan wilayah memiliki kaitan erat dengan perkembangan ekonomi dan pembangunan fisik material, akibat dikuasainya wilayah-wilayah baru sebagai asset pengembangan dinasti. Di dalam konteks sejarah Dinasti Umayyah, pembangunan fisik-material paling tidak memiliki kaitan dengan: bangunanbangunan sarana ibadah dan keagamaan, seperti masjid dan madrasah (maktab), bangunan-bangunan sarana publik, dan pembangunan kota. Ketiga-tiganya dalam konteks sejarah Dinasti Umayyah tidak dapat dilepasan dari pengaruh perluasan wilayah di berbagai kawasan Arab dan luar Arab. ${ }^{1}$ Sehingga karena adanya perluasaan wilayah tersebut akan berpengaruh pada perkembangan arsitektur pada suatu dinasti.

Perkembangan Arsitektur tidak lepas dari pengaruh bentuk dan konsep yang lebih dahulu ada, sehingga pengembangan dan percampuran bentuk dari tempat dan zaman berbeda adalah hal yang lazim.Percampuran semakin kompleks dengan perkembangan budaya manusia, terutama dalam aspek perhubungan. Semakin banyak dilihat dan pengalaman, maka percampuran budaya semakin cepat dan kompleks. ${ }^{2}$

Perkembangan Arsitektur Islami khususnya masjid, semakin kompleks karena kecenderungan memasukkan budaya daerah (vernacularisme). Percampuran bermacam elemen arsitektur untuk pembangunan masjid terlihat antara lain dengan dipakainya kubah yang sudah ada sejak abad I M, pada zaman Romawi dipakai dan dikembangkan pada zaman Bizantium sejak abad III M dan zamanzaman berikutnya. Awal perkembangan Islam abad VII M bersamaan dengan masa kejayaan Imperium Bizantium (abad III-XVI M), maka penggunaan kubah

${ }^{1}$ Nurul Hak, Sejarah Peradabaan Islam, (Yogyakarta: Gosyen Publishing, cet. 1, 2012), h. 120

${ }^{2}$ Yulianto Sumalyo, Arsitektur Masjid dan Monumen Sejarah Muslim, (Yogyakarta: UGM Press, 2006), h. 24 
cukup menonjol dalam arsitektur Masjid. ${ }^{3}$

Di pembahasan penulis akan dipaparkan mengenai sekilas tentang Dinasti Umayyah di Damaskus, kemudian akan dijelaskan mengenai Khalifah Abdul Malik dan Walid I, tentang kebijakan sosial yang mereka tetapkan. Di pembahasan selanjutnya penulis akan menjelaskan mengenai sejarah masjid, yang didalamnya akan dijelaskan mengenai aritektur dan pengaruh gaya aristektur yang akan mempengaruhi pembangunan masjid dan renovosi pada masa Abdul Malik dan Walid I, salah satunya pengaruh dari Persia dan Bizantium. Di pembahasan selanjutnya akan di jelaskan tentang Kubah Batu yang di bangun oleh Abdul Malik bin Marwan, Masjid Damaskus pada masa Walid bin Abdul Malik, dan renovasi yang di lakukan oleh Khalifah Abdul Malik dan Walid I terhadap masjid Nabawi dan Masjid al-Haram.

\section{Sekilas Dinasti Umayyah Sebelum Abdul Malik bin Marwan}

Bani Umayyah adalah salah satu dari keluarga suku Quraisy, keturunan Umayyah ibn Abdul Syams ibn Abdul Manaf, seorang pemimpin suku Quraisy yang terpandang. Umayyah bersaing dengan pamannya, Hasyim ibn Abdul Manaf dalam memperebutkan kehormatan dan kepemimpinan masyarakat Quraisy. Umayyah dinilai memiliki cukup persyaratan untuk menjadi pemimpin dan dihormati oleh masyarakatnya. Ia berasal dari keluarga bangsawan kaya yang mempunyai sepuluh putra. Pada zaman pra-Islam, orang yang memiliki ketiga kelebihan itu berhak memperoleh kehormatan dan kekuasaan. ${ }^{4}$

Sebagian besar anggota keluarga Bani Umayyah menentang Nabi Muhammad SAW yang menyampaian agama Islam, sedangkan keluarga Bani Hasyim membelanya meskipun ada di antara mereka yang belum memeluk Islam. Bani Hasyim membelanya terutama atas dasar ikatan kekerabatan, karena Nabi SAW berasal dari keluarga Bani Hasyim. Tradisi Arab pra-Islam, membela dan melindungi anggota keluarga merupakan tanggung jawab seluruh anggota keluarga. ${ }^{5}$

Setelah Nabi Muhammad pindah dari Mekkah ke Madinah dan berhasil mendapatkan pengikut di kota tersebut, sikap permusuhan Bani Umayyah belum berakhir. Mereka memimpin orang Quraisy Mekkah untuk menentang dan memerangi Nabi SAW serta pengikutnya. Peperangan pun terjadi beberapa

\footnotetext{
${ }^{3}$ Ibid.

${ }^{4}$ Abd Chair (ed.) dkk., Ensiklopedi Tematis Dunia Islam jilid 2, (Jakarta: Ictiar Baru van Haeve,t.t), h. 63

${ }^{5}$ Ibid.
} 
Millatī, Journal of Islamic Studies and Humanities, Vol. 2, No. 2, Des. 2017: 195-220

kali, namun mereka tidak berhasil mengalahkan Nabi SAW. Permusuhan Bani Umayyah berakhir setelah Nabi SAW dan para pengikutnya berhasil memasuki kota Mekkah pada tahun $8 \mathrm{H} / 630 \mathrm{M}$. Mereka tidak mampu melawan, akhirnya Bani Umayyah menyerah kepada Nabi SAW dan menyatakan bersedia masuk Islam. Bani Umayyah tergolong yang belakangan masuk Islam. Setelah masuk Islam, mereka memperlihatkan loyalitas dan dedikasi tinggi terhadap agama tersebut. Setiap peperangan yang dilakukan oleh kaum Muslim misalnya, mereka tampil dengan semangat kepahlawannan, seolah-olah ingin mengimbangi keterlambatan mereka masuk Islam dengan berbuat jasa besar kepada Islam. ${ }^{6}$

Nama Dinasti Umayyah (661-750 M) itu berasal dari nama Umayyah ibn 'Abdi Syams ibn 'Abdi Manaf, yaitu salah seorang dari pemimpin-pemimpin kabilah Quraisy dizaman jahiliyah. ${ }^{7}$ Dinasti Umayyah ini didirikan oleh Mu'awiyah ibn Abi Sofyah. Mu'awiyah ibn Abu Sofyan (606-681 M) pembangun Dinasti Umayyah dan menjabat sebagai khalifah pertama (661-681 M) dari dinasti tersebut.

Mu'awiyah dikenal sebagai pemimpin yang tegas dan keras, tetapi penuh toleransi dan lapang dada. sifat demikian melapangkan jalan bagi Mu'awiyah untuk memperkukuh posisi politik yang telah dicapainya. Ia juga dikenal sebagai dermawan yang rela mengorbankan hartanya untuk menyenangkan hati orang. ${ }^{8}$

Pada masa pemerintahan Mu'awiyah terjadi beberapa penaklukan, penaklukan di masa pemerintahannya demikian luas dan meliputi dua front utama yaitu wilayah barat dan kawasan timur. Wilayah barat mencakup wilayah Romawi (Turki). Dia berhasil menaklukan pulau Jarba di Tunisia pada tahun 669 M, kepulauan Rhodesia pada tahun 673 M, kepulauan Kreta pada tahun $624 \mathrm{M}$, dan kepulauan Ijeh dekat Konstantinopel pada tahun 680M. Di Afrika, Benzat berhasil ditakulkan pada tahun 661 M, Qamuniyah ditaklukan pada tahun 665 M, Susat juga ditaklukan pada tahun yang sama. Uqbah ibn Nafi' berhasil menaklukan Sirt dan Mogadishu, Tripoli, dan menaklukan Waddan. Kur sebuah wilayah di Sudan (berkulit hitam) berhasil pulas ditaklukan, Akhirnya, penaklukan sampai ke wilayah Maghrib Tengah (Aljazair). ${ }^{9}$

Kawasan Timur (negeri-negeri Asia Tengah dan Sindh), negeri-negeri

${ }^{6}$ Ibid., h. 63

${ }^{7}$ A. Syalabi, Sejarah dan Kebudayaan Islam 2, (Jakarta Pusat: Pustaka Al Husna, 1992), h. 24.

${ }^{8}$ Abd Chair (ed.) dkk., Ensiklopedi Tematis Dunia Islam jilid 2, (Jakarta: Ictiar Baru van Haeve,t.t), h. 66

${ }^{9}$ Ahmad al-Usairy, Sejarah Islam Sejak Zaman Nabi Adam hingga Abad XX, terj. Samson Rahman, (Jakarta: Akbarmedia, 2013), hlm 188-189 
Asia Tengah meliputi kawasan yang berada di antara Sungai Saihun dan Jaihun. Pasukan menyerang wilayah Asia Tengah pada tahun $661 \mathrm{M}$. Pada tahun $663 \mathrm{M}$ mereka mampu menaklukan S'ajistan sebagai wilayah Thakharistan pada tahun 665 M. Pada tahun 664 M kaum Muslim menyerang wilayah Sindh dan India. Penduduk di tempat itu selalu melakukan pemerontakan, sehingga membuat kawasan itu tidak selamanya stabil kecuali di masa pemerintahan Walid ibn Abdul Malik..$^{10}$ Mu'awiyah meninggal pada tahun 679 M. Setelah memerintah selama 20 tahun.

Setelah Mu'awiyyah wafat, kekhalifahan pindah ke tangan Yazid. Masa kekuasaan Yazid sangat singkat yaitu pada 680-683 M. Periode Yazid ditandai dengan tiga keburukan dan hanya berbuat satu kebaikan, dalam buku M. Abdul Karim Sejarah Pemikiran dan Peradaban Islam. Pada tahun pertama masa kekuasaan Yazid ibn Mu'awiyah, cucu nabi, Husen terbunuh di Karbala menyebabkan golongan Syi'ah lahir secara sempurna dan menjadi penentang utama kekuasaannya. Pada tahun kedua, tentara Yazid menyerang habis-habisan kota Madinah dalam peperangan di Harra yang mengakibatkan citra Islam tercoreng. Pada tahun ketiga kekuasaannya, tentara Yazid menyerang dan membakar Ka'bah. hal-hal tersebut dilakukan karena tidak diakuinya Yazid sebagai khalifah dari para sahabat termasuk Husen, Abdullah ibn Zubair menjadi khalifah mereka. Pada masa pemerintahannya satu kebaikan, yaitu mengangkat kembali Uqbah ibn Nafi'i menjadi gubernur kedua kalinya di Ifriqiyah/Qayrawan. Yazid meninggal dunia pada 24 September $683 \mathrm{M}$.

Mu'awiyah II menjadi khalifah setelah ayahnya meninggal pada tahun 683 M. Sedangkan masa pemerintahannya sangatlah pendek. Kemudian dia menggundurkan diri karena sakit dan fisiknya lemah. Dia menyendiri di rumahnya hingga dia meninggal setelah 3 bulan menjadi khalifah. ${ }^{11}$

Pemerintahan dilanjutkan oleh Marwan ibn Hakam 683-685 M. Marwan adalah seorang yang bijaksana, berpikiran tajam, fasih berbicara, dan berani. Ia ahli dalam pembacaan al-Qur'an, dan banyak meriwayatkan hadis-hadis dari para sahabat Rasulullah yang terkemuka, terutama dari Umar ibn Khattab dan Utsman ibn Affan. Ia juga telah berjasa dalam menertibkan alat-alat takaran dan timbangan. ${ }^{12}$ Setelah pemerintahannya digantikan oleh Abdul Malik ibn Marwan 685-705 M.
${ }^{10}$ Ibid., h. 189
${ }^{11}$ Ibid., h. 194
${ }^{12}$ Ibid., h. 67. 
Millatī, Journal of Islamic Studies and Humanities, Vol. 2, No. 2, Des. 2017: 195-220

\section{Abdul Malik bin Marwan dan Walid bin Abdul Malik}

\section{Abdul Malik bin Marwan}

Abdul Malik dianggap sebagai pendiri Dinasti Umayyah Kedua, karena mampu mencegah disintegrasi yang telah terjadi sejak masa Marwan. ${ }^{13} \mathrm{Abdul}$ Malik ibn Marwan dilahirkan di Madinah pada tahun $26 \mathrm{H}$, pada masa Khalifah Utsman ibn Affan, ia terkenal sebagai orang yang berani, Fasih didalam pembicaraan memiliki pengetahuan yang banyak, terutama dalam soal agama, seperti fiqh, tafsir, hadits, dan juga hafal al-Qur'an..$^{14}$ Abdul Malik meningggal pada tahun $705 \mathrm{M}$, setelah sukses menjabat pemerintahan selama 21 tahun.

Pada masa pemerintahan Abdul Malik dilakukan peresmian penggunaan bahasa Arab. Semua urusan surat-menyurat dalam diwan-diwan wilayah, dahulunya dengan bahasa Persia dan Romawi, diganti dengan bahasa Arab. Peraturan ini berlaku di seluruh Syam dan Persia. Usaha Abdul Malik yang demikian itu amat besar pengaruhnya terhadap kemajuan bahasa Arab, sehingga ia menjadi bahasa pengetahuan, terutama dalam ilmu hisab (hitungan) dan riyadhat (matematika). ${ }^{15}$ Seiring dengan itu pada masa Abdul Malik jalannya pemerintahan ditentukan oleh empat departemen pokok (diwan). Keempat departemen (kementerian) itu ialah: a) Diwan al-Kharraj (Kementerian Pajak Tanah) yang tugasnya mengawasi departemen keuangan; 2) Diwan al-Khatam (Kementerian Khatam) yang bertugas merancang dan mengesahkan ordonansi pemerintah. Sebagaimana masa Mu'awiyah telah diperkenalkan materai resmi untuk memorandum dari khalifah, maka setiap tiruan dari memorandum itu dibuat, kemudian ditembus dengan benang, disegel dengan lilin, yang akhirnya dipres dengan segel kantor; 3) Diwan al-Rasail (Kementerian Surat Menyurat), dipercayakan untuk mengontrol permasalahan di daerah-daerah dan semua komunikasi dari gubernur-gubernur; 4) Diwan al-Mustagallat (Kementerian urusan perpajakan). ${ }^{16}$

Pada masa Abdul Malik meningkatkan pelayanan pos dan komunikasi, dimana ia membangun kantor pos dan ditugasi kepada seorang dinas pos. Para

${ }^{13}$ Siti Maryam, (ed.) dkk., Sejarah Peradaban Islam dari Masa Klasik hingga Modern, (Yogyakarta: LESFI, cet. 2, 2004), h. 69.

${ }^{14}$ M. Noor Matdawan, Lintas Kebudayaan Islam Periode Khalifah Mua'wiyah dan Abbasiyyah, ( Yogyakarta: Yayasan Bina Karier, 1989), h. 12

15 Siswati Dardiri, Sejarah dan Kebudayaan Islam Daulat Bani Umayyah, (Yogyakarta: Sumbangsih Offset, 1991), h. 56.

${ }^{16}$ Maryam, dkk (ed.), Sejarah, h. 72. 
kepala dinas pos segera mengirim berita penting untuk merangkap mengurusi surat-surat biasa. ${ }^{17}$

\section{Walid bin Abdul Malik}

Setelah Abdul Malik wafat, kemudian digantikan Walid ibn Abdul Malik naik tahta di Damaskus pada tahun 705 M. Pemerintahannya merupakan masa yang lebih aman dan makmur. Walid ibn Abdul Malik di dalam usia 34 tahun menjabat khalifah dengan sebutan Khalifah al-Walid I (705 M- 715 M) dan memerintah sepuluh tahun lamanya. Masa pemerintahannya terpandang zaman keemasaan dan puncak kebesaran Dinasti Umayah sepanjang Sejarah Islam.

Pada masa Walid ibn Abdul Malik, ia mengumpulkan anak yatim, memberi mereka jaminan hidup, dan menyediakan guru untuk mengajari mereka. ${ }^{18}$ Ia juga memajukan pendidikan dengan mendirikan sejumlah sekolah dan mendirikan rumah sakit, juga mendirikan sejumlah panti jompo, panti tunanetra, dan panti cacat. Ia mendirikan rumah sakit khusus bagi penyandang buta, lumpuh, dan gila. ${ }^{19}$ Walid I juga membangun jalan raya, terutama jalan ke Hedzjaz. Di sepanjang jalan itu digali sumur untuk menyediakan air bagi orang yang melewati jalan. Untuk mengurus sumur-sumur tersebut ia mengangkat pegawai. ${ }^{20}$

\section{Sejarah Awal Masjid}

Perluasan wilayah memiliki kaitan erat dengan perkembangan ekonomi dan pembangunan fisik material, akibat dikuasainya wilayah-wilayah baru sebagai asset pengembangan dinasti. Di dalam konteks sejarah Dinasti Umayyah, pembangunan fisik-material paling tidak memiliki kaitan dengan: bangunanbangunan sarana ibadah dan keagamaan, seperti masjid dan madrasah (maktab), bangunan-bangunan sarana publik, dan pembangunan kota. Ketiga-tiganya dalam konteks sejarah Dinasti Umayyah tidak dapat dilepasan dari pengaruh perluasan wilayah di berbagai kawasan Arab dan luar Arab. ${ }^{21}$

${ }^{17}$ M. Abdul Karim, Sejarah Pemikiran dan Peradaban Islam, ( Yogyakarta: Bagaskara, cet. 3, 2011), h. 118.

${ }^{18}$ Ensiklopedi Tematis Dunia Islam, h. 70

${ }^{19}$ Ali, Sejarah, h. 299.

${ }^{20}$ Ensiklopedi Tematis Dunia Islam, h. 70

${ }^{21}$ Nurul Hak, Sejarah Peradabaan Islam, (Yogyakarta: Gosyen Publishing, cet. 1, 2012), hlm 120 
Millatī, Journal of Islamic Studies and Humanities, Vol. 2, No. 2, Des. 2017: 195-220

Di dalam bukunya Hasan Ibrahim Hasan Sejarah Kebudayaan Islam yang diterjemahkan oleh H. A. Bahauddin, mengutip pendapat pendapat Sir Thomas Arnold, bahwa masjid selalu dijadikan sebagai tempat untuk membahas soal-soal politik dan kemasyarakatan. Masjid bukan hanya sebagai tempat menyampaikan pidato keagamaan, tempat mengagungkan Allah, tempat menyampaikan shalawat kepada Nabi, tempat memohon rahmat bagi sahabat, dan tempat melantik khalifah sebagai pengganti Rasulullah SAW, dalam memelihara agama saja, melainkan sebagai tempat seinggasana khalifah, atau kursi gubernur, atau kantor hakim.

Masjid merupakan tempat untuk melaksanakan ibadah kaum musliminin menurut arti luas. Sebagai bagian dari arsitektur, masjid merupakan konfigurasi dari segala kegiatan kaum muslim dalam melaksanakan kegiatan agamanya. ${ }^{22}$ Pembangunan masjid merupakan karakteristik utama dalam proses perkembangan peradaban Islam. Sejak masa Nabi Muhammad SAW di Madinah. Langkah utama dan pertama yang dilakukan nabi adalah membangun masjid. Hal ini menunjukkan bahwa pembangunan peradaban Islam terkait erat dengan spiritualitas umat yang berdasarkan tauhid. Proses pembangunan peradaban Islam diawali dari asas spiritual tauhid ini, yang kemudian berkembang dan berkaitan dengan berbagai aspek kehidupan material dan lainnya. Masjid sebagai sarana utama pembinaan umat, sejak awal kenabian Muhammad SAW di Madinah berfungsi bukan hanya sebagai tempat beribadah, melainkan tempat berbagai aktifitas untuk tujuan syi'ar dan penyiaran agama Islam. ${ }^{23}$

Masjid yang pertama yang dibuat oleh Nabi Muhammad SAW di Madinah adalah Masjid Quba. Masjid ini awalnya merupakan pelataran yang kemudian dipagari dengan dinding tembok yang cukup tinggi kemudian pada sisi bagian utaranya memanjang ke timur-barat didirikan bangunan untuk melakukan ibadah sholat. ${ }^{24}$

Masjid pertama yang dibuat oleh Nabi Muhammad SAW sangat sederhana. Denahnya merupakan masjid yang segi empat dengan hanya dinding-dinding yang menjadi pembatas sekelilingnya. Disepanjang bagian dalam dinding tersebut dibuat semacam serambi yang langsung bersambungan dengan lapangan terbuka sebagian dari bagian tengah masjid segi empat tersebut. Sedangkan bagian pintu masuknya

${ }^{22}$ Abdul Rachym, Mesjid dalam Karya Arsitektur Nasional Indonesia, (Bandung: Angkasa, 1983), h. 15

${ }^{23}$ Hak, Sejarah, h. 120-121

${ }^{24}$ Zein M. Wiryoprawiro, Perkembangan Arsitektur Masjid di Jawa Timur, (Surabaya: Bina Ilmu, 1986), h. 15. 
diberi tanda dengan gapura atau gerbang yang terdiri dari tumpukan batu-batu yang diambil dari sekeliling tempat itu. Bahan-bahan yang dipergunakan adalah material apa adanya sekedar yang terdapat di sekeliling tempat itu, sehingga amat sederhana mutu bahan-bahan yang dipergunakan itu, seperti batu-batu alam atau batu-batuan gunung, pohon, dahan dan daun kurma. ${ }^{25}$

Batu-batu tersebut disusun dan diterapkan dengan memakai campuran tanah liat sebagai perekatnya. Sedangkan pelepah dan daun kurma dipergunakan sebagai atap penutup dan merupakan bahan utama, guna menaungi serambiserambi yang ada di sekeliling bagian dalam dinding pembatas lapangan. Namun demikian justru masjid ini yang merupakan prototype dari masjid-masjid di mana kemudiannya, bahkan menjadi pola dasar yang utama bagi masjid-masjid yang dibangun kemudian. ${ }^{26}$

Pertama arah Sholat ke arah Utara dari kota Madinah, menunjuk arah Aqsa di Jerussalem, karena belum ada wahyu Allah tentang kiblat untuk Sholat. Baru kemudian turun perintah Tuhan melalui surat al-Baqarah (2): 144, menurut terjemah Al-Quran ke dalam bahasa Indonesia berbunyi:

"Sungguh kami melihat wajahmu (Muhammad) sering menengadah ke langit, maka akan Kami palingkan enkau ke Kiblat yang engkau senangi. Maka hadapkanlah wajahmu kearah Masjidilharam. Dan di mana saja engkau berada, hadapkanlah wajahmu kearah itu. Dan sesungguhnya orang-orang yang diberi kitab (Taurat dan Injil) tahu, bahwa (pemindahan kiblat) itu adalah kebenaran dari Tuhan mereka. Dan Allah tidak lengah terhadap apa yang mereka kerjakan."

Masjid Quba ini berbentuk segi empat panjang berpagar tembok tinggi. Rasulullah memproyeksikan pembangunan oleh beliau sendiri. Atapnya dari pelepah kurma dan tiang-tiangnya dari batang pohon kurma serta tingginya seukuran tinggi umumnya orang. Di Masjid ini beliau membangun shuffah, yaitu suatu bagian dari masjid yang dipergunakan sebagai kediaman orang-orang faqir dari kalangan kaum muslimin. Masjid beliau dibangun dengan dua pintu depan, dan satu pintu belakang. Di samping masjid tersebut, beliau membangun beberapa rumah yang terbuat dari tanah liat dan langit-langitnya dari batang pohon kurma. ${ }^{27}$

Enam tahun lamanya bangunan masjid tetap seperti itu, tak ada yang dirubah sederhana. Pada tahun ketujuh hijriah, yaitu sesudah menang dalam

\footnotetext{
${ }^{25}$ Rochym, Sejarah, h. 26

${ }^{26}$ Ibid., h. 26-27

${ }^{27}$ Hasan Ibrahim Hasan, Sejarah dan Kebudayaan Islam 2, terj. H. A. Bahauddin (Jakarta: Kalam Mulia, 2001), h. 433
} 
Millatī, Journal of Islamic Studies and Humanities, Vol. 2, No. 2, Des. 2017: 195-220

penakulkan Khaibar, masjid itu mulai diperbaiki dan diperluas karena jama'ah bertambah banyak. Perluasan masjid dengan panjangnya 35 meter dan dengan lebarnya 30 meter. ${ }^{28}$ Kemudian dibuat sebuah mimbar yang mempunyai dua buah anak tangga. Demikianlah keadaan Masjid Madinah, sampai Nabi wafat. Pada masa khalifah Abu Bakar masjid itu masih tetap seperti demikian, belum ada perubahan yang penting. Perubahan yang terjadi adalah sebagian tiang-tiang yang menyangga diganti karena rusak dimakan bubuk. ${ }^{29}$

\section{Arsitektur}

Arsitekur menurut Banhart CL dan Jess Stein, adalah seni dalam mendirikan bangunan termasuk didalamnya segi perencanaan, konstruksi, dan penyelesaian dekorasinya, sifat atau bangunan, proses membangun, bangunan dan kumpulan bangunan. Menurut Van Romondt arsitektur adalah ruang tempat hidup manusia dengan bahagia. Ruang berarti menunjuk pada semua ruang yang terjadi karena dibuat oleh manusia atau juga ruang yang terjadi karena proses alam seperti gua, naungan pohon dan lain-lain. ${ }^{30}$ Menurut kamus besar bahasa Indonesia arsitektur adalah seni dan ilmu merancang serta membuat konstruksi bangunan, jembatan, dan sebagainya.

Pemahaman dari arsitektur harus memperhatikan tradisi rakyat atau tradisi yang disenangi masyarakat, bangunan-bangunan yang disebut primitif atau asli yang selalu merupakan bagian terbesar dari lingkungan buatan dan yang hakiki bagi setiap generalisasi yang absah, dan yang pasti penting untuk suatu pembahasan tentang asal mula. Kebudayaan menyangkut sekelompok manusia yang memiliki seperangkat nilai dan keyakinan dan suatu pandangan terhadap dunia yang mewujudkan suatu cita-cita. Arsitektur terutama sekali merupakan hasil dari faktor-faktor sosial budaya, dan dengan definisi tentang perancangan yang mencakup pengubahan-pengubahan yang paling berguna terhadap lingkungan fisik. Arsitektur dapat dianggap sebagai suatu konstruksi yang dengan sengaja mengubah lingkungan fisik menurut suatu bagan pengaturan. ${ }^{31}$

${ }^{28}$ C. Israr, Sejarah Kesenian Islam jilid 1, (Jakarta: Bulan Bintang, cet. 2, 1978), h. 78

${ }^{29}$ Ibid., h. 79

${ }^{30}$ Agung Wijarnako, 2013, "Pengertian Arsitektur Menurut Para Ahli" dalam http:// architectureinhand.blogspot.co.id diunduh pada 25 Januari 2015.

${ }^{31}$ James C. Snyder dan Anthony J. Catanese, Pengantar Arsitektur, terj. Hendro Sangkoyo (Jakarta: Erlangga, 1991), h. 13-15. 
Arsitektur merupakan titik tumpu dari hasil usaha orang-orang yang melahirkannya, serta merupakan suatu konsepsi yang sesuai dengan keadaan, tingkat kecakapan serta penghayatan masyarakat terhadap arsitektur tersebut pada suatu saat tertentu. Sebagai penampilan yang berwujud, arsitektur sangat erat kaitannya dengan aktivitas kehidupan manusia, baik berupa jasmani maupun rohani. Pada hakikatnya arsitektur dilahirkan untuk memenuhi kebutuhan manusia. Dengan demikian maka arsitektur akan senantiasa berhubungan dengan masalah-masalah adat kebiasaan, mengikuti pola kehidupan, yang disertai dengan keterampilan untuk mewujudkannya. ${ }^{32}$

Pada arsitektur harus ditambahkan faktor kegunaan yang menyertainya secara relevan dengan penampilannya sebagai keperluan untuk memenuhi kebutuhan manusia. Arsitektur juga bersentuhan dengan zaman tertentu, karena arsitektur merupakan arsip visual dari keadaan zaman tersebut, bahkan dapat memberikan gambaran yang jelas tentang ukuran tinggi rendahnya kehidupan masyarakat pada saat itu. Gambaran visual pada arsitektur identik dengan corak dan sifat kehidupan masyarakat yang membuatnya, sehingga masyarakat yang hidup di kemudian hari akan mengetahui apa yang terjadi pada masa lalu. ${ }^{33}$ Sehingga setiap daerah dan penguasa memiliki corak dan ciri khas sendiri dalam bangunannya. Kemajuan arsitektur atau bangunan sebagai tanda bahwa adanya kemajuan dan peradaban suatu kerajaan. Bangunan dan arsitektur merupakan salah satu bukti adanya peradabaan disuatu daerah tersebut dan mengalami masa kejayaan.

\section{Pengaruh Persia}

Hasil dari seni Persia yang paling kuno, yaitu Keramik, patung-patung, berbagai barang dari perunggu dan lain-lain (5.000-1.000 SM), seni lukis, dan arsitektur (550 SM - 1.600 M). Masa-masanya dapat dibagi sebagai berikut: Pertama, pada masa Dinasti Akhaeminid (sampai tahun 350 SM). Kedua, pada masa Dinasti Seleukos dan Arsacid (sampai kira-kira 250 SM). Ketiga, pada masa Dinasti Sassanid (sampai kira-kira tahun $650 \mathrm{M}$ ). Di antara sisa-sisa peninggalannya, yaitu istana bergaya iwan, yang dibelakangnya didirikan belairung berkubah, jembatan-jembatan dengan busur meruncing, gambar-gambar timbul pada bukit berbatu, barang-barang perak anggun, beberapa tenunan dari sutra dan lain-lain. ${ }^{34}$ 1983), h. 2

${ }^{32}$ Abdul Rachym, Mesjid dalam Karya Arsitektur Nasional Indonesia, (Bandung: Angkasa,

${ }^{33}$ Ibid., h. 2-3.

${ }^{34}$ Samsul Munir Amin, Sejarah Peradaban Islam, (Jakarta: AMzah, cet. 2, 2010), h. 54-55 
Millatī, Journal of Islamic Studies and Humanities, Vol. 2, No. 2, Des. 2017: 195-220

Islam menerima warisan budaya arsitektur dari wilayah di sebelah timur. Unsur arsitektur Persi dan Hindustani mendominasi ragam warisan tersebut. Budaya arsitektur Persiani berangkat dari karakter Sassanian berbasis arsitektur Sumerian-Mesopotamian yang banyak menggunakan material bata bakar.

Ranah Sassania mulai disentuh ketika Khalifah Umar ibn Khattab menundukan kekaisaran Persia dengan keberhasilan memenangkan pertempuran di Qadisiah. Kebijakan mengembangkan Islam di wilayah tersebut dengan membangun pusat kegiatan di Kufah dan Basra membuat kaum Muslimin dari waktu ke waktu bergaul dengan budaya Persia. ${ }^{35}$ Masjid bergaya Persia bisa dilihat dari ciri khasnya, yaitu pilar batu batataman yang luas, dan lengkungan yang disokong beberapa pilar. ${ }^{36}$

\section{Pengaruh Bizantium}

Kerajaan Romawi didirikan pada tahun 753 SM, dengan ibu kotanya Roma, dan usianya lebih sepuluh abad. Bulan Mei $30 \mathrm{M}$ terjadi perpecahan dalam Kerajaan Romawi yang berpusat di Roma, yaitu pecah menjadi dua kerajaan; Kerajaan Romawi Barat (Roma) dan Kerajaan Romawi Timur, dengan ibu kota Konstantinopel. Kerajaan Romawi mengalami puncak kejayaan pada masa Maharaja Yustianus I (527-565 M), dan pada zamannya terjadi peperangan dengan Kerajaan Persia Sassanid. ${ }^{37}$ Kekaisaran Romawi barat mengalami kemunduran, sebaliknya kekaisaran Romawi Timur dengan ibukota Konstantinopel terus berkembang, dan pada zaman pertengahan menjadi benteng kaum Kristiani terhadap serbuan bangsa Barbarian Sllavia dari barat, dan serangan kaum muslim dari Timur. ${ }^{38}$

Gaya arsitektur Bizantium yang bermula pada abad VI ini tumbuh dari berbagai dasar dan akar kebudayaan. Pertama, gaya klasik seni Romawi Hedonis yang tidak berbau keagamaan. Kedua, budaya pembuatan makam bawah tanah gaya gereja Kristen-Romawi dari Abad II - III. Ketiga, banyaknya pembangunan gereja Kristen Kuno di Yunani. ${ }^{39}$ Adanya pengaruh Arsitektur Romawi terhadap Arsitektur Muslim, karena perluasan wilayah. Gaya Arsitektur Bizantium yang

${ }^{35}$ Acmad Fanani, Arsitektur Masjid, (Yogyakarta: Benteng Pustaka, 2009), h. 47.

${ }^{36}$ Chairul Akhmad, 2014 "Arsitektur Islam dan Pengaruh budaya lokal" dalam http:// www.republika.co.id diunduh 01 Agustus 2015 pukul 16:40 WIB.

${ }^{37}$ Amin, Sejarah, h. 48

38 Sukawi, 2004, "Arsitektur Bizantiumn pada Dome of The Rock", Jurnal Jurusan Arsitektur Universitas Diponegoro Semarang, Vol. 1 No. 2- Desember 2004, h. 2

${ }^{39}$ Ibid., h. 3 
bermula pada abad kelima hingga saat ini, dicirikan oleh perkembangan gaya baru dari kubah untuk menutup bidang polygon atau persegi untuk gereja, makam, dan tempat pembabtisan. Penggunaan sistem kubah untuk konstruksi atap bertolak belakang dengan gaya Kristiani kuno berupa penopang-penopang kayu dan juga gaya lengkungan batu romawi. Cita-cita arsitektur Bizantium adalah mengkonstruksi atap gereja dengan atap kubah dianggap symbol dari kekuasaan yang Maha Esa.Bangsa Bizantium meniru dari bangsa Sassanid dari Timur, yang membangun kubah-kubah diatas bujursangkar, walau ukurunannya sangat kecil. ${ }^{40}$

Pada pembangunan Kubah Batu yang dirancang oleh Abdul Malik ibn Marwan, dibangun antara tahun 687-692 M, melalui arsitek-arsitek beraliran Bizantium di bawah pengawasan lapangan dari ahli-ahli bangunan siria dan ahli-ahli dekorasi mozaik dari konstantinopel. ${ }^{41}$

Ciri khas dari arsitektur Bizantium adalah dengan adanya bentuk persegi yang bagian atasnya berupa kubah. Hal tersebut diterapkan dalam desain Kubah Batu. Di dalam dekorasi bangunan monumental itu banyak terdapat mozaikmozaik yang menunjukkan perpaduan motif-motif Sasanid dan Bizantium yang merupakan karakteristik seni Islam awal. Bahan material yang digunakan pada ornamen Kubah Batu banyak menggunakan marmer, mozaik, keramik bahkan tidak sedikit yang dilapisi emas. Ruang dalam banyak mempunyai ciri khas gaya Bizantium yaitu dihiasi secara mewah dengan beraneka ragam warna dan bahan material pada ornamennya. ${ }^{42}$

Arsitektur Bizantium yang diterapkan terutama sebagai arsitektur gereja dan arsitektur bernapas kristiani pada waktu itu ternyata dapat diterapkan sebagai arsitektur masjid, yang mempunyai islami dengan fungsi yang sama yaitu ibadah, serta tidak menghilangkan nilai-nilai arsitekturnya. Hal ini menunjukkan arsitektur Bizantium dapat bersifat fleksibel dan universal. Penggunannya tidak terbatas dalam bentuk gereja, biara, tempat pembabtisan ataupun istana. ${ }^{43}$

Pengaruh tradisi bangunan Kristiani tampak pada tampilan bangunan Kubah Batu. Bentuk rotunda mengingatkan pada bentuk rotunda gereja-gereja yang berkembang di wilayah Syiria sejak tahun 400 M. Meskipun dinding luar Kubah Batu berbentuk segi delapan sementara rotunda gereja berbentuk bulat, namun komposisi ruang dalamnya dengan kehadiran kolonade (jajaran kolom)

\footnotetext{
${ }^{40}$ Ibid., h. 3-4

${ }^{41}$ Sumalyo, Arsitektur, h. 49

42 Ibid., h. 10

${ }^{43}$ Ibid., h. 12
} 
Millatī, Journal of Islamic Studies and Humanities, Vol. 2, No. 2, Des. 2017: 195-220

melingkar mengitari ruang utama serta posisi portikonya memiliki kesamaan yang dekat. ${ }^{44}$

Pengaruh lain pada Masjid Damaskus. Masjid Damaskus adalah salah satu contoh bagaimana umat Kristiani mengubah bangunan Kuil Yupiter dari tradisi Romawi menjadi gereja, kemudian ketika kaum Muslimin menguasai wilayah itu menjadikannya sebagai masjid. Banyak bangunan asli dibiarkan utuh dan tetap dipakai, sementara beberapa bagaian lain disesuaikan untuk keperluan ibadah shalat berjama'ah. Demikian juga dengan tradisi ragam hias dekoratifnya. Sebelum Islam menemukan jati diri ragam hias dekoratifnya yang khas, Masjid Agung Damaskus memanfaatkan lukisan dinding floral natural dari tradisi gaya Bizantium. ${ }^{45}$

Percampuran arsitektur Romawi, Kristen Awal dan muslim terlihat pada konstruksi dan dekorasi, antara lain kolom-kolom Corinthian ${ }^{46}$ hiasan intricate $e^{47}$ dan arabesque. Pada pintu utama dan pengapitnya, dibawah pelengkung disangga oleh kolom-kolom silinderis model Romawi Corinthian. Di atas tiga pintu terdapat pelengkung besar dan tiga jendela berambang juga melengkung yang lebih berfungsi sebagai hiasan. Unsur ini juga banyak terdapat pada Arsitektur Romawi dan gereja-gereja Kristen Awal. ${ }^{48}$

\section{Kubah Batu dan Masjid Damaskus}

\section{Kubah Batu}

Pada masa pemerintahan Abdul Malik ibn Marwan ada beberapa kemajuan yang dicapai.Kemajuan di bidang politik, ekonomi, dan arsitektur. Kemajuan arsitektur pada masa Abdul Malik ini ditandai dengan didirikannya masjid "Kubah Batu" (The Dome of the Rock/Qubat as-Shkhrah) di Yerusalem, yang sampai sekarang masih terjaga sebagai salah satu peninggalan arsitektur Islam masa awal. ${ }^{49}$ Masjid ini merupakan masjid pertama yang ditutup dengan kubah di atasnya.

${ }^{44}$ Fanani, Arsitekttur, h. 30-31.

${ }^{45}$ Ibid., h. 30

${ }^{46}$ Corinthian merupakan salah satu gaya dari arsitektur Yunani dan Romawi dengan cirri antara lain kolom langsing, kepala kolom dihiasi dengan pola Floral (bercorak Tanaman).

${ }^{47}$ Intricate merupakan ornament biasanya berwarna-warni, terdiri dari jalinan garis-garis geometris menerus membentuk pola geometris pula.

${ }^{48}$ Sumalyo, Arsitektur, h. 61

${ }^{49}$ K. Ali, Sejarah Islam (Tarikh Pramodern), terj. Ghufron A. Mas'adi, (Jakarta: Raja Grafindo Persada, cet. 3, 2003), h. 287. 
Yerusalem berada di perbatasan Israel dan Yordania, hingga saat ini menjadi kota dalam sengketa antara Israel, Yordania dan Palestina. Yerusalem dipandang sebagai kota suci oleh banyak agama, bagi kaum muslim menjadi kota penting karena pada masa Nabi Muhammad SAW pada suatu malam bertolak mengadakan perjalanan ke surga dengan Buraq. peristiwa ini disebut sebagai Isra' Mi'raj. Bagi kaum Nasrani Yerusalaem adalah kota suci di mana Yesus Kristus, disalib dan bangkit di Surga. ${ }^{50}$

Yerusalem tercatat dalam sejarah sejak abad Sembilan belas dan delapan belas SM menjadi tempat bermukim orang-orang Kanaan (Canaanite).Pada Yerusalem memasuki periode Hellenic di bawah kekuasaan Yunani hingga awal abad I. Kemudian dilanjutkan zaman Romawi menjadi bagian dari pemerintahan Roma. Pada abad IV Yerusalem dikuasai Bizantium, Konstantin yang agung (Constantine the Great), menjadikan Yerusalem sebagai kota suci Kristen. Persia mengalahkan Bizantium, menaklukkan dan menguasai Yerusalem pada 614 M. ${ }^{51}$

Bizantium kembali menguasai Yerusalem pada 629 M, namun tidak lama orang-orang Semenanjung Arab menyerang dan menaklukan Yerusalem. Selanjutnya terjadi peralihan kekuasaan dari Khalifah Ali ibn Abi Thalib (656-661 M) ke Mu'awiyah yang sebelumnya gubernur di Siria (661 - 680 M). Sepanjang sejarah sejak Islam masuk pada 638 hingga 1917 Yerusalaem tidak pernah menjadi ibukota pemerintahan dari suatu Negara merdeka, tetapi hanya selalu menjadi pusat propinsial..$^{52}$

Pada masa Yerussalem dikuasai oleh Abdul Malik ibn Marwan beliau mengambil kebijakaan diantaranya pembangunan masjid Kubah Batu. Ketika Khalifah Abdul Malik memutuskan untuk membangun Kubah Batu, ia datang dari Damaskus ke Yerusalem dan mengirim surat kepada gubernur di provinsi-provinsi. Menyatakan bahwa ia ingin membangun Kubah diatas batu, untuk melindungi dari panas dan dingin. Akan tetapi sebelum melakukannya, ia ingin mengetahui tanggapan dari masyarakat. Setelah itu ia mendapat balasan bahwa mereka senang akan dibangun masjid agar mendapat pelindungan dari Allah SWT. ${ }^{53}$

Masjid Kubah Batu dibangun antara tahun 687 hingga 692 M, dibangun oleh para arsitek beraliran Bizantium di bawah pengawasan lapangan oleh ahli-

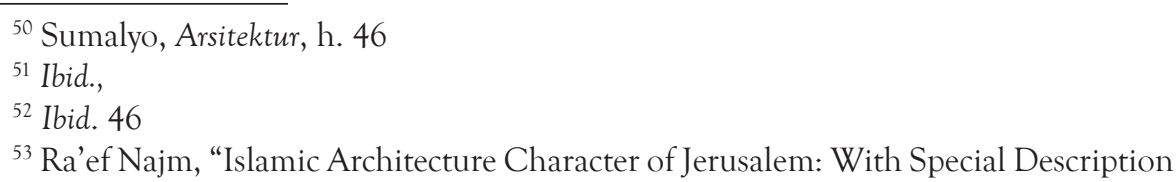
of the al-Aqsa and the Dome of The Rock", Islamic Studies, Vol. 40, No. 3/4, Special Issue Jerusalem (Autumn-Winter 2001), h. 725. 
Millatī, Journal of Islamic Studies and Humanities, Vol. 2, No. 2, Des. 2017: 195-220

ahli bangunan dari Siria dan ahli-ahli dekorasi mozaik dari konstantinopel. Kubah Batu, terletak di tengah halaman suatu kompleks, atau lebih tepat dikatakan lapangan karena sangat luas. ${ }^{54}$

Pada 687 - 692 M Abdul Malik ibn Marwan membangun Kubah Batu, menurut pengelana dan ahli geografi Abad X al-Maqdisi, sang khalifah menginginkan bangunan megah yang menandingi keindahan Gereja Makam Suci, dan untuk menciptakan bangunan unik yang merupakan keajaiban dunia bagi kaum muslim. Dia membangun Kubah Batu sebagai tempat ziarah. ${ }^{55}$

Masjid yang dibangun oleh Khalifah Abdul Malik ibn Marwan salah satunya adalah Masjid Kubah Batu. Kubah Batu yang berada di tengah agak ke sisi barat dari Lapangan Temple Mount, diatas pelataran lebih tinggi dari lapangan.Perancangan Kubah Batu sangat mendasarkan pada perhitungan geometris terutama dalam menentukan bentuk dan titik-titik pada denah. ${ }^{56}$

Arsitektur bangunan Kubah Batu merupakan sebuah perubahan radikal dari bangunan berpola lama, yang melibatkan penggunaan mosaik dan motif dekorasi lainnya.Pembangunan Kubah itu dimaksudkan untuk mengungguli atap gereja Sepulchre Suci yang indah.Hasilnya, sebuah monument arsitektur yang keindahannya tak tertandingi. ${ }^{57}$

Kubah Batu mempunyai kubah oktagonal (bersegi delapan) bertinggilebar $20 \mathrm{~m}$, yang disangga oleh susunan 12 tinggi dan 4 penyangga melintang, dalam koridor oktagonal dengan 16 tiang dan 8 penyangga melintang, serta tembok luar yang juga oktagonal. Masing-masing dari kedelapan sisi luar dinding kira-kira bertinggi $11 \mathrm{~m}$ dan berlebar $8 \mathrm{~m}^{58}$

Dekorasi internal dari Kubah Batu mempunyai mosaik yang indah pada periode Umayyah. Mosaik yang membentang di atas delapan dinding yang mempunyai panjang 240 meter, terdiri dari kaligrafi mosaik kufi yang berwarna biru. Sedangkan dekorasi eksternal terbuat dari marmer dan mosaik. ${ }^{59}$

\footnotetext{
${ }^{54}$ Sumalyo, Arsitektur, h. 48-49.

${ }^{55}$ Ranna Bokhari dan Mohammad Seddon, Ensiklopedia Islam, (Jakarta: Erlangga, t.t), h. 66 .

${ }^{56}$ Sumalyo, Arsitektur, h. 49.

${ }^{57}$ Philip K. Hitti, History of The Arabs, terj. R. Cecep Lukman Yasin dan Dedi Slamet Riyadi (Jakarta: Serambi Ilmu Semesta, cet. 1, 2013), h. 331.

${ }^{58}$ Raana Bokhari dan Mohammad Seddon, Ensiklopedia, h. 66.

${ }^{59}$ Ra' ef Najm, "Islamic Architecture Character of Jerusalem: With Special Description of the al-Aqsa and the Dome of The Rock", Islamic Studies, Vol. 40, No. 3/4, Special Issue Jerusalem (Autumn-Winter 2001), h. 726
} 
Kubah dari Kubah Batu ini didukung oleh empat buah pilar utama.Pada mulanya masjid ini tidak berdinding, sebab konsentrasi pembuatannya adalah untuk menjadikan kubah sebagai penutup batu suci yang ada di tengah-tengah sebagai titik pusat bangunan. Dindingnya baru kemudian ditambahkan sebagai pengisi di antara pilar-pilar yang berdiri di atas denah segidelapan tersebut dari bahan ringan dan miring ke atas, yang seoalah-olah membawa pandangan menuju ke Kubah yang besar, serta keseluruhan permukaannya dilapisi dengan emas tipis. ${ }^{60}$

Pintu masuk ke dalam Kubah Batu ada empat buah, pada setiap arah mata angin: utara, barat, timur dan selatan. Pintu utama berada di selatan di mana ada Masjid Al-Aqsa yang pintu masuknya dalam satu garis sumbu dengan pintu utara dan selatan Kubah Batu.Semua pintu terlindungi oleh Kanopi, yang pada pintu utama lebih besar, ditopang oleh delapan kolom silinsris dari Marmer. ${ }^{61}$

Kubah Batu, dari depan dengan pintu masuk utama terlindungi oleh tritisan pelengkung. Semua dinding tertutup marmer atau dekorasi, yang merupakan satu-satunya ciri muslim dalam bangunan ini bercorak kaligrafi, geometris intricate ${ }^{62}$, floral ${ }^{63}$ dan arabesque ${ }^{64}$. Tidak sedikit bagian-bagian dekorasinya menggunakan lapisan emas.

Kubah batu memiliki Mihrab, sesuai dengan arah kiblat, berada di salah satu sisi segi delapan yang di tenggara, namun tidak ada mimbar. Kubah Batu lebih berfungsi sebagai monument Islam dibandingkan sebagai masjid, corak arsitekturnya tidak terlalu khas bangunan ibadah muslim. ${ }^{65}$

\section{Masjid Damaskus}

Sebelum di kuasai Islam, Damaskus merupakan pusat pemerintahan Romawi di Syiria. Pada masa Dinasti Umayyah dijadikan ibu kota negara, yang pada masa Nabi dan al-Khulafaur Rasyidin berkedudukan di Madinah. Khalifah Mu'awiyah memindahkan ibu kota tersebut, karena wilayah Syiria sebagai h. $70-71$.

${ }^{60}$ Abdul Rochym, Sejarah Arsitektur Islam Sebuah Tinjauan, (Bandung: Angkasa,1983),

${ }^{61}$ Sumalyo, Arsitektur, h. 50.

${ }^{62}$ Ornamen biasanya berwarna warni, terdiri dari jalinan garis-garis geometris menerus membentuk pola geometris.

${ }^{63}$ Floral, merupakan bercorak tanaman, dari suatu hiasan baik berupa batang merambat melengkung-lengkung, daun, bunga, buah atau lain-lain.

${ }^{64}$ Arabesque Hiasan lengkung-lengkung dan geometris penyederhanaan bentuk dan tanaman melengkung-lengkung.

${ }^{65}$ Sumalyo, Arsitektur, h. 52. 
Millatī, Journal of Islamic Studies and Humanities, Vol. 2, No. 2, Des. 2017: 195-220

basisnya, sebelumnya Mu'awiyah menjadi gubernur di Syiria selama 20 tahun. ${ }^{66}$ Pada masa kepemimpinan Walid ibn Abdul Malik memiliki beberapa kebijakaan diantaranya membangun Masjid di Damaskus, karena kecintaannya atau kesenangannya terhadap dunia arsitektur. Arsitek terbesar Dinasti Umayyah adalah pada masa Walid ibn Abdul Malik putra dari Abdul Malik ibn Marwan. Pada masa pemerintahannya relatif damai dan sejahtera. Khalifah Walid memilki kecenderungan yang sedemikian besar terhadap arsitektur, sehingga selama masa pemerintahannya, ketika orang Damaskus berkumpul bersama tema obrolan mereka berkisar pada bangunan-bangunan indah. ${ }^{67}$ Khalifah Walid ibn Abdul Malik menata kembali kota dengan menambah bangunan-bangunan baru, terutama yang berhubungan dengan kepentingan umum.

Pada tahun 705 M, putra dari Abdul Malik, Walid ibn Abdul Malik, mengambil alih kawasan gereja Romawi di Damaskus yang dibangun untuk Santo Yahya, pada mulanya merupakan kuil Jupiter, dan membangun masjid besar yang diberi nama Masjid Umayyah. ${ }^{68}$ Masjid ini termasuk salah satu bangunan Islam yang terindah. Bahkan ada yang menjulukinya sebagai salah satu keajaiban dunia. Asal mulanya masjid ini merupakan rumah pemujaan bangsa Yunani yang didirikan sekitar tahun 1000 SM, kemudian oleh orang Nasrani diubah menjadi gereja, kemudian oleh orang Islam dijadikan masjid. ${ }^{69}$

Ketika Khalid ibn Walid merebut kota Damaskus dari tangan bangsa Romawi, kemudian sebagian gereja tersebut dipakai sebagai Masjid, sedangkan sebagian lagi tetap sebagai gereja Nasrani. Jadi pada waktu itu gedung ini dipakai sebagian untuk masjid dan sebagian untuk gereja. Setelah umat Islam bertambah banyak, sedangkan orang Nasrani berkurang, maka gedung atau gereja tersebut dibangun dan dijadikan masjid, sedangkan orang-orang Kristen menggunakan gereja lain. ${ }^{70}$

Pembangunan masjid mengubah total tata letak bangunan sebelumnya. Rumah ibadah baru itu dimaksudkan untuk menampung jamaah yang besar bagi warga Damaskus.Masjid selesai pada 715M , setelah kematian Walid, oleh penggantinya, Sulaiman bin Abdul Malik (715-717M) masjid itu dituntaskan pembangunannya. ${ }^{71}$

\footnotetext{
${ }^{66}$ Susmihara dan Rahmat, Sejarah Islam Klasik, (Yogyakarta: Ombak, 2013), h. 167

${ }^{67}$ Hitti, History, h. 276.

${ }^{68}$ Ibid.,h. 332.

${ }^{69}$ C. Israr, Sejarah Kesenian Islam jilid 1,(Jakarta: Bulan Bintang, cet. 2, 1978), h. 110

${ }^{70}$ Ibid.,h. 111

71 "Masjid Umayyah Damaskus, Saksi Bisu Perjuangan Islam hingga Turunnya Nabi
} 
Masjid Damaskus dijadikan Walid I sebagai salah satu simbol kebesaran Arsitektur Islam. Ia sengaja menghiasnya sebaik-baiknya hingga tampak megah dan memperlihatkan keagungan Islam. Pembangunannya menghabiskan dana yang begitu besar sampai mengundang kritik dari Masyarakat. Pembangunan Masjid Damaskus ini menghabiskan seluruh masa pemerintahan Walid, bahkan masih menyisakan beberapa bagian yang belum selesai, yang pada akhirnya diselesaikan oleh Khalifah Sulaiman ibn Abdul Malik adiknya. ${ }^{72}$ Al-Walid I mengeluarkan dana untuk pembangunannya sebesat tujuh tahun hasil pajak negara. Langkah ini ditempuhnya sebagai amal agama yang sangat mulia untuk mendekatkan diri kepada Allah SWT. ${ }^{73}$

Masjid Damaskus atau masjid Umayyah yang dibangun oleh Walid ibn Abdul Malik. Prestasi Walid terbesar adalah mengubah fungsi Katedral St. Yahya Pembabtis di Damaskus yang ia mengambil alih dari penduduk Kristen, menjadi masjid yang sangat agung. ${ }^{74}$ Di masjid Damaskus terdapat dua menara. Dua menara Masjid sebelah selatan pada awalnya merupakan menara gereja Romawi kuno, tapi menara sebelah utara, yang awalnya merupakan menara pendeta, memang dibangun al-Walid I dan menjadi model menara di Suriah, Afrika Utara dan Spanyol. Ia merupakan menara tertua yang dibangun oleh orang Islam. ${ }^{75}$

Tembok keliling dirombak sehingga terbentuk pola hypostyle ${ }^{76}$ seperti Masjid Nabi dan Masjid Agung Kufa, yaitu berupa sebuah sahn yaitu halaman dalam berbentuk segi empat dikelilingi oleh bagian bangunan beratap. Unit utama ditutup oleh konstruksi dari tiga atap berjejer melintang masing-masing berbentuk pelana, bersambung langsung satu dengan lain. ${ }^{77}$

Unit utama simetris terdiri dari sayap barat, sayap timur dan bagian tengah di mana terdapat pintu utama. Unit utama ini berhadapan langsung dengan batu-batu lempengan. Sayap barat dan timur, bagian depannya terdiri dari pilaster berjajar, di antara pilaster masing-masing ada pelengkung dan Isa di Akhir Zaman”, dalam http:// www.eramuslim.com diunduh pada Senin, 6 Juli 2015, pukul 09:40 WIB

${ }^{72}$ Abdussyafi Muhammad Abdul Latif, Bangkit dan runtuhnya Khalifah Bani Umayyah, terj. Masturi Irham dan Malik Supar (Jakarta: Pustaka al-Kautsar,2014), h. 201.

${ }^{73}$ Hasan, Sejarah, h. 437

${ }^{74}$ Hitti, History, h. 277.

${ }^{75}$ Ibid.,h. 332.

${ }^{76}$ Hypostyle, tata ruang bangunan biasanya segi empat dikelilingi di kiri-kanan oleh riwaq.

${ }^{77}$ Sumalyo, Arsitektur, h. 58. 
Millatī, Journal of Islamic Studies and Humanities, Vol. 2, No. 2, Des. 2017: 195-220

sebuah pintu. Konstruksi, bentuk dan ornament-ornamen bagian depan sangat jelas mendapat pengaruh arsitektur Romawi. ${ }^{78}$ Di dalam masjid inilah mihrab berbentuk setengah lingkaran muncul untuk pertama kalinya.Dalam masjid ini juga ditemukan pintu berbentuk tapal kuda. ${ }^{79}$ Mihrab pada Masjid Damaskus berhiaskan permata, lalu di atas mihrab tersebut tergantung lampu emas dan perak. Mihrab juga dihiasi oleh mozai dan berantaikan emas. ${ }^{80}$

Di tengah terdapat bagian beratap pelana, melintang tegak lurus terhadap sayap kiri kanan, dimana terdapat pintu masuk utama. Pintu utama diapit oleh pintu lebih kecil, berada di bawah pelengkung disangga. Di atas ketiga pintu terdapat pelengkung besar dan tiga jendela berambang juga melengkung yang berfungsi sebagai hiasan. Bidang disekeliling pelengkung besar dihias dengan ornament Mozaik, bermotif pohon dan bangunan-bangunan. ${ }^{81}$

Ada ornament yang unik tidak terdapat pada Masjid maupun bangunan lain pada umumnya, dari mozaik menggambarkan kesejukan sungai yang mengalir di kota dan kehijauan pohon. Riwaq menyatu dengan dinding dimana terdapat pintu masuk dan kedua riwaq juga bertiang membentuk deretan pelengkung gaya Romawi. ${ }^{82}$

Pada halaman atau pelataran dalam di perkeras oleh lanatai dari batu licin, terdapat air mancur, satu ditengah lainnya dikiri dan kanan untuk wudhu. Bila dilihat lengkapnya unsur-unsur dalam masjid ini antara lain, orientasi kearah kiblat, ruang ibadah berjamaah, mihrab, mimbar, minaret, air mancur untuk berwudhu bahkan adanya kubah. ${ }^{83}$

\section{Perluasaan Masjid al-Haram dan Masjid Nabawi}

Umar ibn Khattab merebut kota Yerusalem pada tahun 638 dari tangan Bizantium dan dengan mengadakan perjanjian dengan kaum Nasrani agar tidak menghancurkan gereja-gereja yg ada di dalamnya. Khalifah Umar ibn Khatab kemudian meninjau batu tempat Mi' rajnya Rasulullah SAW (kini ada di dalam Dome of Rock - bangunan berkubah warna emas), kemudian mendirikan masjid Umar untuk

${ }^{78}$ Ibid., h. 58.

${ }^{79}$ Hitti, History, h. 334.

${ }^{80}$ Hasan Ibrahim Hasan, Sejarah dan Kebudayaan Islam 2, terj. H. A. Bahauddin (Jakarta: Kalam Mulia, 2001), h. 439

${ }^{81}$ Sumalyo, Arsitektur, h. 61-62

${ }^{82}$ Ibid.,

${ }^{83}$ Sumalyo, Arsitektur, h. 61-62. 
shalat, yang kini menjadi Masjid Al Aqsa (berkubah warna abu-abu). Pada masa periode Khalifah Umayyah, tahun 691-692 Abdul Malik ibn Marwan membangun bangunan yang sekarang dikenal dengan Kubah Batu dan 2 tahun kemudian memperluas Masjid Umar menjadi Masjid Al Aqsa. Pembangunan diteruskan oleh anaknya, Al-Walid Ibn Abdul Malik. ${ }^{84}$ Masjid al-Aqsa terletak di Kompleks Temple Mounth atau Haram al-Sharif (Sebelah selatan-barat Masjid Kubah Batu).

Pada masa Dinasti Umayyah melakukan perbaikan-perbaikan terhadap masjid-masjid tua yang telah ada sejak zaman Rasulullah. Khalifah Abdul Malik ibn Marwan menyediakan dana 10.000 dinar mas untuk memperluas Masjid al-Haram, kemudian al-Walid menyempurnakan perbaikannya dengan memperhatikan aspek-aspek estetiknya seperti membuat pintu dan jendela lengkung, berukir dan tiang-tiangnya dibuat dari batu granit. ${ }^{85}$

Masjid paling suci kaum muslim adalah Masjid al-Haram di Mekkah, mengelilingi Kabah menjadi kiblat dimana saja orang Islam melakukan ibadah. Mekkah dan Kabah menjadi unsur pemersatu umat Islam baik secara keagamaan maupun kebudayaan. ${ }^{86}$ Masjid suci ini terbangun di sekitar Ka'bah yang dibangun oleh Nabi Ibrahim AS dan merupakan bagian yang tak terpisahkan dari padanya. Pada masa Nabi Muhammad SAW, memperluas masjid al-Haram ini dengan membeli rumah-rumah yang ada di sekitarnya ${ }^{87}$

Kabah sejak $638 \mathrm{M}$ dikelilingi dinding, agar dapat terbentuk ruang tawaf, berjalan mengeliling Kabah tujuh kali berlawanan dengan arah jarum jam sambil berdoa.Pada $646 \mathrm{M}$ ruang tawaf diperluas dengan dinding baru dengan pelengkung-pelengkung (arcade) untuk masuk ke halaman depan. Pada tahun 707 Khalifah Walid menutup arcades dengan atap dari kayu di atas kolom-kolom marmer. ${ }^{88}$

Pada masa Khalifah Walid ibn Abdul Malik, Masjid al- Haram disempurnakan kembali bangunannya.Aspek estetika sudah mulai diperhatikan.Pintupintu dan jendela-jendela dibuat melengkung (arcade) dengan ukiran-ukiran yang indah di atasnya, dari motif-motif geometris dan daun-daunan dan ayat-ayat al-Qur'an. Tiang-tiang masjid yang indah bentuknya terbuat dari batu granit yang halus.Saqaf atau plafonnya dihiasi denganukiran-ukiran yang indah. Usaha

84 "Sejarah Masjidil Aqsa \& Jerusalem (Baitul Maqdis)" dalam http://www.carakawisata. com diunduh Minggu, 12 Juli 2015 pukul 10:30 WIB.

${ }^{85}$ Maryam, (ed.),Sejarah, h. 76.

${ }^{86}$ Sumalyo, Arsitektur, h. 36.

${ }^{87}$ Susmihara, Sejarah, h. 168-169

${ }^{88}$ Ibid. 
Millatī, Journal of Islamic Studies and Humanities, Vol. 2, No. 2, Des. 2017: 195-220

perluasannya, dan penyempurnaannya dilanjutkan oleh khalifah Abbasiyah. ${ }^{89}$

Selain merenovasi masjid al-Haram, Walid I juga merenovasi masjid Nabawi. Renovasi yang dilakukan oleh Walid I ini merupakan kali kelima dalam pembongkarannya. Walid I melakukan pembongkaran besar-besaran dengan memperluas area Masjid Nabawi. Perluasan yang dilakukan ke arah timur masjid. Pembongkaran Masjid Nabawi ini dilakukan di tahun $77 \mathrm{H} .{ }^{90}$ Pelaksanaan pembangunan ini dipercayakan kepada saudara sepupunya yang menjadi gubernur Madinah, Umar ibn Abdul Aziz, yang kemudian menugaskan Shalih ibn Kaisan untuk mengawasi pembanguan Masjid Nabawi. ${ }^{91}$

Al-Walid I mengirim surat kepada kekaisaran Romawi meminta agar dikirim para ahli bangunan untuk membangun Masjid Nabawi. Kemudian ia mengirim empat puluh orang Romawi dan empat puluh orang Qibthi. Kekaisaran Romawi juga mengirim empat puluh ribu mitsqal emas dan kepingan granit. Mereka membangun pondasi, dinding, dan tiang-tiang masjid dari batu, juga penompang masjid terbuat dari batu bertulang besi dan timah. Pembangunan Masjid Nabawi, mihrab dan mimbarnya terbuat dari kayu jati. Kemudian pembangunan Masjid Nabawi dilakukan oleh orang muslim. ${ }^{92}$

Perluasan masjid yang dilakukan ke sebelah timur, dindingnya berbatasan dengan bilik-bilik istri Nabi dan sekaligus dengan makan Rasulullah dan dua sahabatnya, Abu Bakar As-Siddiq dan Umar bin Khattab. Sehingga membuat makam mereka di masukkan kedalam area masjid. Dinding masjid pun mengalami perubahan. Dinding masjid bagian luar mirip dengan bangunan benteng yang mirip dengan pembatasan antara dunia luar dan dunia dalam. Dinding ini dari luar tidak begitu mengalami renovasi, akan tetapi dari dalam akan terlihat perbedaannya, karena di tambah dengan eleman ceruk kecil pada dinding di bagian kiblatnya. Kemudian bagian inilah yang berkembang menjadi elemen mihrab. ${ }^{93}$

Mihrab cerukan pada dinding masjid sebagai penunjuk arah shalat, ditambahkan dalam struktur bangunan masjid yang meniru arsitektur gereja. Al-Walid dan gubernurnya Umar ibn Abdul Aziz, dipandang sebagai orang pertama yang memperkenalkan struktur tersebut. Masjid Madinah atau Masjid

\footnotetext{
${ }^{89}$ Ibid., h. 169.

${ }^{90}$ Fanani, Arsitektur, h. 185

${ }^{91}$ Lathif, Bangkit, h. 201.

${ }^{92}$ Hasan, Sejarah, h. 434

${ }^{93}$ Fanani, Arsitektur, h. 185-186
} 
Nabi merupakan masjid pertama yang memiliki mihrab. Struktur tersebut kemudian menjadi karakteristik umum di semua masjid dan seperti halnya altar kristen, dipandang sebagai lokasi paling sakral. Dengan demikian, mihrab menjadi bagian utama dari berbagai bentuk dekorasi orang Islam. ${ }^{94}$

Al-Walid I merubah penampilan dari masjid Nabawi dengan sebelumnya dan memiliki perubahannya pada saat itu. Pada renovasi saat itu, al-Walid I menambahkan empat menara pada setiap sudutnya, empat menara ini dibuat lebih tinggi dari dinding yang lain, serta dilakukan penebalan di empat titiknya. Selain itu, renovasi pada masjid ini atap dari masjid. Pada penopang atap juga mengalami perkembagan, pilar-pilar yang terdapat pada penopang atap terdiri dari kolom-kolom penyangga dan pasangan balok pendukung, mengalami evolusi bentuk secara konsisten. ${ }^{95}$

Di bawah gubernur Umar ibn Abdul Aziz, memperkenalkan minaret dan balkon pada masjid. Perluasan oleh Walid ibn Abdul Malik, panjang dan lebar masing-masing bertambah $90 \mathrm{~m}$ sehingga luas penambahan $2369 \mathrm{~m}^{2}$. Menurut sejarawan ibn Qodamah, dalam pembangunan ini Walid mendapat bantuan 40 orang buruh, 40 tenaga berbagai keahlian, emas dan Mozaik dikirim oleh Raja Roma. ${ }^{96}$ Pada renovasi, dinding Masjid ini dihiasi mozaik dan batu permata. Tiangnya dari batu marmer, lantainya dari batu Pualam, plafonnya bertatahkan emas murni, ditambah empat buah menara. ${ }^{97}$

\section{Kesimpulan}

Dinasti Umayyah (661 - 750 M) didirikan oleh Mu'awiyah ibn Abu Sofyan (661 - 681 M) yang merupakan Khalifah pertama pada masa Dinasti Umayyah. Mu'awiyah ibn Abu Sofyan menjabat menjadi khalifah selama kurang lebih 20 tahun. Pada masa Dinasti Umayyah ibukota dipindahkan ke Damaskus yang sebelumnya pada masa Ali ibn Abi Tholib ibukota berada di Kuffah.

Pada masa kekuasaan Abdul Malik ibn Marwan khalifah ke-5 dari dinasti Umayyah membangun Masjid yaitu Kubbah batu karang. Masjid ini terletak di Yerussalem dengan bentuk bangunan oktagonal. Bangunan ini didirikan dimana di yakini di tempat itu di mana Nabi Muhammad naik ke langit pada saat menjalankan Isra' Mi'raj. Setelah Abdul Malik wafat pemerintahan digantikan

\footnotetext{
${ }^{94}$ Hitti, History, h. 327.

${ }^{95}$ Fanani, Arsitektur, h. 186

${ }^{96}$ Sumalyo, Arsitektur, h. 31.

${ }^{97}$ Maryam,dkk (ed.), Sejarah, h. 76.
} 
Millatī, Journal of Islamic Studies and Humanities, Vol. 2, No. 2, Des. 2017: 195-220

oleh putranya Walid ibn Abdul Malik.

Pada masa Walid ibn Abdul Malik melakukan beberapa konstribusi didalam hal bangunan. Pada masa Khalifah Walid mengambil alih kawasan gereja Romawi Santi Yahya, yang pada mulanya merupakan kuil Jupiter, dan membangun masjid besar yang diberi nama Umayyah. Pembangunan Masjid mengubah total tata letak bangunan sebelumnya, masjid ini dibangun untuk menampung jama'ah yang besar bagi warga Damaskus. Selain itu, pada masa khalifah Walid melakukan beberapa renovasi terhadap bangunan sebelumnya. Diantaranya Masjid yang direnovasi Masjidil Haram yang disempurnakan kembali bangunannya, dengan memperhatikan aspek estetika. Kemudian masjid yang direnovasi kembali adalah Masjid Nabawi, ia memperluasnya dari semua sisi, serta memasukkan beberapa bilik istri-istri nabi ke dalam area masjid tersebut.

Masjid Kubah Batu dan Masjid Damaskus mendapat beberapa pengaruh kebudayaan dari luar. Kebudayaan itu antara lain kebudayaan Romawi dan Kebudayaan Persia. Bangunan Romawi memili ciri khas dibuatnya Kubah tanpa adanya kolom penyonkong untuk menutupi ruangan. Ciri khas dari bangunan masjid Persia adalah pilar batu bata, taman yang luas, dan lengkungan yang disokong beberapa pilar.

\section{Daftar Pustaka}

\section{Buku}

A. Syalabi. Sejarah dan Kebudayaan Islam 2. Jakarta Pusat: Pustaka Al Husna, 1992. Abd Chair (ed.) dkk. Ensiklopedi Tematis Dunia Islam jilid 2. Jakarta: Ictiar Baru van Haeve,t.t.

Abdussyafi Muhammad Abdul Latif. Bangkit dan runtuhnya Khalifah Bani Umayyah. terj. Masturi Irham dan Malik Supar. Jakarta: Pustaka al-Kautsar,2014.

Abdul Rochym. Sejarah Arsitektur Islam Sebuah Tinjauan. Bandung: Angkasa,1983. Acmad Fanani. Arsitektur Masjid. Yogyakarta: Benteng Pustaka, 2009.

Ahmad al-Usairy. Sejarah Islam Sejak Zaman Nabi Adam hingga Abad XX, terj. Samson Rahman. Jakarta: Akbarmedia, 2013.

C. Israr. Sejarah Kesenian Islam jilid 1. Jakarta: Bulan Bintang, cet. 2, 1978.

Hasan Ibrahim Hasan. Sejarah dan Kebudayaan Islam 2, terj. H. A. Bahauddin. Jakarta: Kalam Mulia, 2001.

James C. Snyder dan Anthony J. Catanese. Pengantar Arsitektur, terj. Hendro 
Sangkoyo.Jakarta: Erlangga, 1991.

K. Ali. Sejarah Islam (Tarikh Pramodern) terj. Ghufron A. Mas'adi . Jakarta: Raja Grafindo Persada, cet. 3, 2003.

M. Abdul Karim. Sejarah Pemikiran dan Peradaban Islam. Yogyakarta: Bagaskara, cet. 3, 2011.

M. Noor Matdawan. Lintas Kebudayaan Islam Periode Khalifah Mua'wiyah dan Abbasiyyah. Yogyakarta: Yayasan Bina Karier, 1989.

Nurul Hak. Sejarah Peradabaan Islam. Yogyakarta: Gosyen Publishing, cet. 1, 2012.

Philip K. Hitti. History of The Arabs, terj. R. Cecep Lukman Yasin dan Dedi Slamet Riyadi. Jakarta: Serambi Ilmu Semesta, 2013.

Ranna Bokhari dan Mohammad Seddon. Ensiklopedia Islam. Jakarta: Erlangga, t.t. Samsul Munir Amin. Sejarah Peradaban Islam. Jakarta: AMzah, cet. 2, 2010.

Siswati Dardiri. Sejarah dan Kebudayaan Islam Daulat Bani Umayyah. Yogyakarta: Sumbangsih Offset, 1991.

Siti Maryam, (ed.) dkk. Sejarah Peradaban Islam dari Masa Klasik hingga Modern. Yogyakarta: LESFI, cet. 2, 2004.

Susmihara dan Rahmat. Sejarah Islam Klasik. Yogyakarta: Ombak, 2013.

Yulianto Sumalyo. Arsitektur Masjid dan Monumen Sejarah Muslim. Yogyakarta: UGM Press, 2006.

Zein M. Wiryoprawiro. Perkembangan Arsitektur Masjid di Jawa Timur. Surabaya: Bina Ilmu, 1986.

\section{Ensiklopedi}

Ensiklopedi Tematis Dunia Islam

\section{Jurnal}

Agung Wijarnako. 2013. "Pengertian Arsitektur Menurut Para Ahli" dalam http://architectureinhand.blogspot.co.id diunduh pada 25 Januari 2015.

Chairul Akhmad. 2014. "Arsitektur Islam dan Pengaruh budaya lokal" dalam http://www.republika.co.id diunduh 01 Agustus 2015 pukul 16:40 WIB.

Ra'ef Najm. "Islamic Architecture Character of Jerusalem: With Special Description of the al-Aqsa and the Dome of The Rock", Islamic Studies, Vol. 40, No. 3/4, Special Issue Jerusalem (Autumn-Winter 2001).

Sukawi. 2004. "Arsitektur Bizantiumn pada Dome of The Rock", Jurnal Jurusan Arsitektur Universitas Diponegoro Semarang, Vol. 1 No. 2-Desember 2004. 
Millatī, Journal of Islamic Studies and Humanities, Vol. 2, No. 2, Des. 2017: 195-220

\section{Internet}

Chairul Akhmad. 2014 "Arsitektur Islam dan Pengaruh budaya lokal" dalam http://www.republika.co.id diunduh 01 Agustus 2015 pukul 16:40 WIB.

"Masjid Umayyah Damaskus, Saksi Bisu Perjuangan Islam hingga Turunnya Nabi Isa di Akhir Zaman", dalam http://www.eramuslim.com diunduh pada Senin, 6 Juli 2015, pukul 09:40 WIB.

. "Sejarah Masjidil Aqsa \& Jerusalem (Baitul Maqdis)" dalam http:// www.carakawisata.com diunduh Minggu, 12 Juli 2015 pukul 10:30 WIB. . "Masjid Umayyah Damaskus, Saksi Bisu Perjuangan Islam hingga Turunnya Nabi Isa di Akhir Zaman”, dalam http://www.eramuslim.com diunduh pada Senin, 6 Juli 2015, pukul 09:40 WIB. 